\title{
Allelic Diversity of HMW and LMW Glutenins in Indian Wheats and Their Relationship with Sedimentation Volume and Mixograph Parameters
}

\author{
S. RAM*, S. SHARMA and I. SHARMA \\ Directorate of Wheat Research, P.O. Box 158, Agrasain Marg, Karnal 132 001, Haryana, India \\ (Received 23 July 2014; Accepted 24 September 2014; \\ Communicated by F. Békés)
}

\begin{abstract}
Two hundred and forty diverse set of wheat cultivars released in India during the last several decades were evaluated for HMW and LMW glutenin alleles, for assessing their diversity and effect on sedimentation volume and mixograph parameters. Both SDS-PAGE and PCR based markers were employed in identifying alleles encoded at Glu-1 and Glu-3 loci. Extensive allelic variation was observed at both the Glu-1 and Glu-3 loci. There was prevalence of Glu-A1b, Glu-B1i, Glu-D1a, Glu-A3c, Glu-B3b, Glu-B3g and Glu-D3b. The alleles Glu-A1b, Glu-B1i, Glu-D1d, Glu-A3b, Glu-B3g/h and Glu-D3b exhibited high SDSsedimentation volume. Glu-Bli and Glu-Dld showed highly significant positive effect $(p<0.001)$ on sedimentation volume and also had additive effects. However, surprisingly overall there was decline in the frequency of $G l u-B 1 i$ allele during last two decades in Indian wheat breeding and not a single $1 \mathrm{~B} / 1 \mathrm{R}$ translocation cultivar possessed this allele. Glu-Alb showed significant positive effect on mixograph peak time, peak slope and peak width. Glu$B 3 g$ exhibited significantly higher mixograph peak time and width at 8 and $G l u-B 3 h$ showed higher dough stability. Glu-B3j (1B/1R translocation) exhibited highest peak slope indicating the negative effect on dough strength. This information can be useful in designing breeding program for the improvement of Indian bread wheat quality.
\end{abstract}

Keywords: glutenins, sedimentation volume, mixograph, allele, wheat

Abbreviations: HMW-GS - high molecular weight glutenin subunits; LMW-GS - low molecular weight glutenin subunits; PCR - polymerase chain reaction

\section{Introduction}

Gluten, the visco-elastic complex of wheat dough, determines the quality of various enduse products of wheat. Gluten is composed of glutenins and gliadins, the major storage proteins in wheat endosperm. Glutenins are divided into high (HMW) and low (LMW) molecular weight glutenins (Payne 1987; Gupta and MacRitchie 1994; Shewry et al. 2003; Maucher et al. 2009) distinguished by their differential mobility on SDS-PAGE. HMW glutenins are encoded by Glu-A1, GluB1 and Glu-D1 loci and LMW glutenins by

* Corresponding author; E-mail: sewaram01@yahoo.com; Phone: +91 1842267495 (Office); Fax: +91 1842267390 
Glu-A3, Glu-B3 and Glu-D3 loci (Payne and Lawrence 1983; Gupta and Shepherd 1990). Many studies have been conducted in assessing the role of HMW-GS in imparting dough strength and extensibility (Branlard and Dardevet 1985; Payne 1987; Gupta and MacRitchie 1994; Luo et al. 2001; Liu et al. 2005; Figueroa et al. 2009). Based on the composition of HMW and LMW glutenin alleles, models were developed for predicting dough strength and extensibility (Cornish et al. 2006). However, inconsistent results obtained for the nomenclature of Glu-3 alleles across the laboratories made it more complicated the assessment of the role of individual LMW-GS alleles and their interactive effects with HMW glutenins (Ikeda et al. 2008). This has been primarily due to the complexity in band patterns of their large numbers and overlapping mobility with the gliadins on SDS-PAGE (Jackson et al. 1996; Igrejas et al. 1999).

Recently, large numbers of LMW glutenin genes have been characterized and several functional markers developed to identify LMW glutenin alleles (Zhang et al. 2004; Zhao et al. 2007a and b; Appelbee et al. 2009; Wang et al. 2009, 2010). Therefore, combining SDS-PAGE methodologies with PCR based markers can be employed in the undisputed classification of many of the LMW glutenin alleles and hence useful in identification of relationship between these alleles and several quality traits (Maucher et al. 2009; Liang et al. 2010; Ram et al. 2011). In the present study, 240 diverse set of wheat cultivars representing different climatic zones in India, were evaluated for HMW and LMW glutenin alleles using both SDS-PAGE and PCR based allele specific markers. Allelic relations of both HMW and LMW glutenin subunits with sedimentation volume and mixograph characteristics individually and in combination were identified. SDS sedimentation volume and mixograph parameters are widely used for evaluating gluten strength and mixing properties, respectively, in bread wheats.

\section{Materials and Methods}

\section{Plant materials}

Two hundred and forty diverse set of wheat cultivars released in India during the last several decades were evaluated for HMW and LMW glutenin alleles and different quality parameters. These cultivars represented the entire wheat production area in India comprising 6 wheat growing zones based on agroclimatic conditions. Among them 81 cultivars were from North Western Plains Zone (NWPZ), 57 from North Eastern Plains Zone (NEPZ), 41 from Central Zone (CZ; Zone III), 30 from Peninsular Zone (PZ; Zone IV) and 31 from Northern Hills Zone (NHZ; Zone V). We had only 4 cultivars from Southern Hills Zone (SHZ; Zone VI) and hence not included in analysis. The material was grown during the two crop seasons of 2008-2009 and 2009-2010 at DWR, Karnal, India.

\section{Identification of $H M W-G S$ and $L M W-G S$}

HMW-GS alleles encoded at Glu-A1, Glu-B1 and Glu-D1 loci were separated on SDSPAGE and classified as per the method of Singh et al. (1991). LMW-GS alleles were iden- 
tified combining both SDS-PAGE and PCR based approach (Wang et al. 2009, 2010; Appelbee et al. 2009; Ram et al. 2011). Glu-B3b alleles were identified using primer combinations developed by Sharma et al. (2013). DNA was isolated as per the modified method of Benito et al. (1993). PCR amplification was performed in a total volume of $20 \mu \mathrm{l}$ containing 50-100 ng of genomic DNA, 1X PCR buffer, $1.5 \mathrm{mM}$ of $\mathrm{MgCl}_{2}, 200 \mu \mathrm{M}$ of each deoxyribonucleotide (dNTP), $100 \mathrm{ng}$ of each primer and $0.3 \mathrm{U}$ of Taq DNA polymerase (Bangalore Genei). PCR amplification conditions were similar to that mentioned by Ram et al. (2011). The amplified fragments were separated on 1.5\% agarose gel, stained with ethidium bromide and visualized using the Gel Documentation System (Bio-Rad). The DNA marker bands were 100, 200, 300, 600, 1000, 1500, 2500, 3000 bp in size.

\section{Analysis of grain and flour quality}

Grain protein content was measured by Foss Infratec ${ }^{\mathrm{TM}} 1241$ Near-Infrared-Reflectance (NIR). The wholemeal flour of the wheat cultivars was produced on a cyclotec mill with a $0.5 \mathrm{~mm}$ sieve and SDS-sedimentation volume was measured by the modified method of Carter et al. (1999). Grain samples were cleaned and tempered based on the $14 \%$ moisture content. Milling was performed in a Brabender Senior Mill to flour extraction rate of around 65\% used for Mixograph analysis. A 10-gm Mixograph (National) was used to assess dough properties and the mixograph curves were computed with the Mixsmart software.

\section{Statistical analysis}

Effect of allelic variation encoded by the Glu-1 and Glu-3 loci on various quality parameters was assessed through ANOVA based on the two years averaged data. Duncan multiple comparisons were employed to group individual alleles based on the effect on sedimentation volume, protein content and mixograph marameters. All computations were completed by SAS software.

\section{Results}

\section{Allelic variation in $H M W-G S$ and $L M W-G S$}

Extensive allelic variation was observed at both the Glu-1 and Glu-3 loci (Table S1*). Allelic frequencies of both HMW-GS and LMW-GS and their distribution in different zones and periods are given in Tables 1 and 2. Among 3 alleles encoded at Glu-A1 locus, $G l u-A 1 b$ was the predominant allele (62.3\%). Out of the 8 alleles observed at Glu-B1 locus three alleles, namely Glu-Bli (34.7\%), Glu-B1b (28.1\%) and Glu-B1c $(26.0 \%)$ were present more frequently. Glu-Dla $(67.5 \%)$ occurred more frequently as compared to Glu-Dld (22.5\%). 82\% of the genotypes with the Glu-Dla allele possessed Glu-A1b while $43 \%$ of the genotypes with the Glu-D1d possessed Glu-A1b. There was no signifi-

\footnotetext{
* Further details about the Electronic Supplementary Material (ESM) can be found at the end of the article.
} 
Table 1. Allelic frequencies and zone-wise distribution of HMW-GS and LMW-GS in Indian wheat cultivars (240)

\begin{tabular}{|c|c|c|c|c|c|c|c|c|}
\hline Locus & Allele & Total No & $\begin{array}{c}\text { Frequency } \\
(\%)\end{array}$ & NWPZ (81) & NEPZ (57) & CZ (41) & PZ (30) & NHZ (31) \\
\hline \multirow[t]{3}{*}{ Glu-Al } & $a$ & 53 & 22.1 & $19(23.5)$ & $10(17.5)$ & $7(16.7)$ & $6(20)$ & $11(35.5)$ \\
\hline & $b$ & 148 & 61.7 & $47(58.0)$ & $40(70.2)$ & $29(69.0)$ & $17(56.7)$ & $16(51.6)$ \\
\hline & $c$ & 39 & 16.2 & $15(18.5)$ & $7(12.3)$ & $6(14.3)$ & $7(23.3)$ & $4(12.9)$ \\
\hline \multirow[t]{6}{*}{ Glu-B1 } & $a$ & 7 & 2.93 & $6(7.4)$ & $1(1.8)$ & $(0.0)$ & $(0.0)$ & $(0.0)$ \\
\hline & $\bar{i}$ & 84 & 35.0 & $30(37.0)$ & $21(36.8)$ & $12(29.3)$ & $15(50.0)$ & $6(19.4)$ \\
\hline & $b$ & 68 & 28.3 & $23(28.4)$ & $19(33.3)$ & $14(34.2)$ & $5(16.7)$ & $7(22.6)$ \\
\hline & $c$ & 63 & 26.3 & $18(22.2)$ & $14(24.6)$ & $5(12.2)$ & $8(26.7)$ & $18(58.1)$ \\
\hline & $e$ & 9 & 3.8 & $(0.0)$ & $1(1.8)$ & $5(12.2)$ & $1(3.3)$ & $(0.0)$ \\
\hline & others & 11 & 4.6 & $4(4.9)$ & $1(1.8)$ & $5(12.2)$ & $1(3.3)$ & $(0.0)$ \\
\hline \multirow[t]{2}{*}{ Glu-D1 } & $a$ & 162 & 67.5 & $51(63.0)$ & $40(70.2)$ & $33(80.5)$ & $18(60)$ & $20(64.5)$ \\
\hline & $d$ & 78 & 32.5 & $30(37.0)$ & $16(28.1)$ & $9(22.0)$ & $12(40)$ & $11(35.5)$ \\
\hline \multirow[t]{4}{*}{ Glu-A3 } & $b$ & 44 & 18.3 & $15(18.5)$ & $9(15.8)$ & $8(19.5)$ & $4(13.3)$ & $8(25.8)$ \\
\hline & $c$ & 156 & 65.0 & $56(69.1)$ & 37 (64.9) & $28(68.3)$ & $18(60.0)$ & $17(54.8)$ \\
\hline & $d$ & 25 & 10.4 & $7(8.6)$ & $8(14.0)$ & $3(7.3)$ & $2(6.7)$ & $5(16.1)$ \\
\hline & $e / f$ & 15 & 6.3 & $3(3.7)$ & $3(5.3)$ & $2(4.9)$ & $6(20)$ & $1(3.2)$ \\
\hline \multirow[t]{6}{*}{ Glu-B3 } & $b$ & 72 & 30.0 & $26(35.8)$ & $15(29.8)$ & $12(34.2)$ & $13(50.0)$ & $6(22.6)$ \\
\hline & $g$ & 60 & 25.0 & $25(30.9)$ & $13(22.8)$ & $8(19.5)$ & $7(23.3)$ & $7(22.6)$ \\
\hline & $h$ & 39 & 16.3 & $7(8.6)$ & $13(22.8)$ & $7(17.1)$ & $5(16.7)$ & $7(22.6)$ \\
\hline & $i$ & 35 & 14.6 & $9(11.1)$ & $10(17.5)$ & $9(22.0)$ & $3(10)$ & $4(12.9)$ \\
\hline & $j$ & 24 & 10.0 & $12(14.8)$ & $6(10.5)$ & $2(4.9)$ & $2(6.7)$ & $6(19.4)$ \\
\hline & others & 10 & 4.2 & $2(2.5)$ & $2(3.5)$ & $3(7.3)$ & $3(10)$ & $(0.0)$ \\
\hline \multirow[t]{6}{*}{ Glu-D3 } & $a$ & 73 & 30.4 & $20(24.7)$ & $15(26.1)$ & $16(39.0)$ & $11(36.7)$ & $11(35.5)$ \\
\hline & $b$ & 76 & 31.7 & $21(25.9)$ & $24(42.1)$ & $10(24.4)$ & $8(26.7)$ & $13(41.9)$ \\
\hline & $g$ & 59 & 24.6 & $24(29.6)$ & $12(21.1)$ & $12(29.3)$ & $7(23.3)$ & 4 (12.9) \\
\hline & $i$ & 17 & 7.1 & $10(12.3)$ & $1(1.8)$ & $2(4.8)$ & $2(6.7)$ & $2(6.5)$ \\
\hline & $j$ & 8 & 3.3 & $4(4.9)$ & $1(1.8)$ & $(0.0)$ & $2(6.7)$ & $1(3.2)$ \\
\hline & others & 7 & 2.9 & $2(2.5)$ & $4(7.0)$ & $1(2.4)$ & $(0.0)$ & $(0.0)$ \\
\hline
\end{tabular}

Notes: Values in bracket are allelic percentage within zone. Others include rare alleles.

NWPZ: North Western Plain Zone; NEPZ: North Eastern Plain Zone; CZ: Central Zone; PZ: Peninsular Zone; NHZ; North Hill Zone.

cant variation in the distribution of HMW-GS alleles encoded at Glu-A1 and Glu-D1 loci in different zones. However, Glu-B1a allele encoded at Glu-B1 locus was present only in cultivars representing northern zones (NEPZ and NWPZ) and Glu-B1i was present at greater frequency in PZ and lower in NHZ. With respect to periods, there was decrease in the frequency of the stronger alleles like Glu-A1b, Glu-B1i and Glu-D1d after 1960. 
Table 2. Frequency of HMW-GS and LMW-GS alleles distributed over 5 decades

\begin{tabular}{|c|c|c|c|c|c|c|c|}
\hline Locus & Allele & Frequency & $\begin{array}{c}1961-1970 \\
(18)\end{array}$ & $\begin{array}{c}1971-1980 \\
(40)\end{array}$ & $\begin{array}{c}1981-1990 \\
\text { (74) }\end{array}$ & $\begin{array}{c}1991-2000 \\
(54)\end{array}$ & $\begin{array}{c}\text { After } 2001 \\
\text { (54) }\end{array}$ \\
\hline \multirow[t]{3}{*}{ Glu-A1 } & $a$ & $53(22.1)$ & $4(22.2)$ & $3(7.5)$ & $11(14.9)$ & $20(37.0)$ & $15(27.8)$ \\
\hline & $b$ & $148(6.7)$ & $10(55.6)$ & $27(67.5)$ & $53(71.6)$ & $25(46.3)$ & $33(61.1)$ \\
\hline & $c$ & $39(16.3)$ & $4(22.2)$ & $10(25)$ & $10(13.5)$ & $9(16.7)$ & $6(11.1)$ \\
\hline \multirow[t]{6}{*}{ Glu-B1 } & $a$ & $7(2.9)$ & $1(5.6)$ & $(0.0)$ & $(0.0)$ & $3(5.6)$ & $3(5.6)$ \\
\hline & $b$ & $68(28.3)$ & $2(11.1)$ & $16(40)$ & $26(35.1)$ & $9(16.7)$ & $15(27.8)$ \\
\hline & $c$ & $63(26.3)$ & $4(22.2)$ & $6(15)$ & 11 (14.9) & $25(46.3)$ & $18(33.3)$ \\
\hline & $e$ & $9(3.8)$ & $1(5.6)$ & $1(2.5)$ & $2(2.7)$ & $2(3.7)$ & $3(5.6)$ \\
\hline & $i$ & $84(35.0)$ & $9(50.0)$ & $15(37.5)$ & 33 (44.6) & $13(24.1)$ & $14(25.9)$ \\
\hline & others & $9(3.8)$ & $1(5.6)$ & $2(5)$ & $2(2.7)$ & $2(3.7)$ & $2(3.7)$ \\
\hline \multirow{3}{*}{ Glu-D1 } & & & & & & & \\
\hline & $a$ & $162(67.5)$ & $9(50.0)$ & $30(75)$ & $59(79.7)$ & $31(57.4)$ & $33(61.1)$ \\
\hline & $d$ & $78(32.5)$ & $9(50.0)$ & $10(25)$ & $15(20.3)$ & $23(42.6)$ & $21(38.4)$ \\
\hline \multirow{4}{*}{ Glu-A3 } & & & & & & & \\
\hline & $\frac{b}{c}$ & $\begin{array}{c}44(18.3) \\
156(65)\end{array}$ & $\frac{1(5.6)}{15(83.3)}$ & $\frac{6(15)}{21(52.5)}$ & $\begin{array}{l}15(20.3) \\
46(62.2)\end{array}$ & $\begin{array}{c}9(16.7) \\
36(66.7)\end{array}$ & $\frac{13(24.1)}{38(70.4)}$ \\
\hline & $d$ & $25(10.4)$ & $2(11.1)$ & $6(15)$ & $9(12.2)$ & $7(13.0)$ & $1(1.9)$ \\
\hline & $e / f$ & $15(6.3)$ & $(0.0)$ & $7(17.5)$ & $4(5.4)$ & $2(3.7)$ & $2(3.7)$ \\
\hline \multirow{6}{*}{ Glu-B3 } & $b$ & $70(29.2)$ & $6(33.3)$ & $12(30)$ & $25(33.8)$ & $7(13.0)$ & $20(37.0)$ \\
\hline & $g$ & $60(25.0)$ & $3(16.7)$ & $14(35)$ & $21(28.4)$ & $9(16.7)$ & $13(24.1)$ \\
\hline & $h$ & $39(16.3)$ & $2(11.1)$ & $8(20)$ & $12(16.2)$ & $10(18.5)$ & $7(13.0)$ \\
\hline & $i$ & 35 (14.6) & $6(33.3)$ & $6(15)$ & $10(13.5)$ & $10(18.5)$ & $3(5.6)$ \\
\hline & $j$ & $24(10.0)$ & $(0.0)$ & $0(0.0)$ & $2(2.7)$ & $15(27.8)$ & $7(13.0)$ \\
\hline & others & $8(3.3)$ & $1(5.6)$ & $0(0.0)$ & $3(4.1)$ & $2(3.7)$ & $2(3.7)$ \\
\hline & & & & & & & \\
\hline \multirow[t]{6}{*}{ Glu-D3 } & $a$ & $73(30.4)$ & $12(66.7)$ & $12(30)$ & $20(27.0)$ & $13(24.1)$ & $16(29.6)$ \\
\hline & $b$ & $76(31.7)$ & $2(11.1)$ & $13(32.5)$ & $21(28.4)$ & $14(25.9)$ & $26(48.2)$ \\
\hline & $g$ & $59(24.6)$ & $2(11.1)$ & $9(22.5)$ & $23(31.1)$ & $18(33.3)$ & $7(13.0)$ \\
\hline & $i$ & $17(7.1)$ & $2(11.1)$ & $2(5.0)$ & $6(8.1)$ & $4(7.4)$ & $3(5.6)$ \\
\hline & $j$ & $8(3.3)$ & $(0.0)$ & $2(5.0)$ & $3(4.1)$ & $3(5.6)$ & $(0.0)$ \\
\hline & others & $7(2.9)$ & $(0.0)$ & $2(5.0)$ & $1(1.4)$ & $2(3.7)$ & $2(3.7)$ \\
\hline
\end{tabular}

Both SDS-PAGE and PCR based markers were employed in identification of LMW glutenin subunit alleles. Four alleles, namely Glu-A3b (18.0\%), Glu-A3c (65.6\%), Glu$A 3 d(10.2 \%)$ and $G l u-A 3 e / f(6.2 \%)$, were identified encoded at Glu-A3 locus. Earlier studies (Jackson et al. 1996; Igrejas et al. 1999; Branlard et al. 2003) reported the presence of the Glu-A3a allele in large numbers of cultivars in Europe. This was because of difficulty in distinguishing Glu-Ala and Glu-Alc alleles on SDS-PAGE. Recently developed PCR markers could distinguish them clearly which showed the presence of the Glu$A 3 c$ allele in a collection of diverse wheat genotypes representing different regions (Zhang et al. 2004; Liu et al. 2010; Wang et al. 2010; Ram et al. 2011). 
Six allelic variants, namely Glu-B3b (36.7\%), Glu-B3d (1.3\%), Glu-B3g (21.1\%), Glu$B 3 h(17.5 \%)$, Glu-B3i (12.6\%), Glu-B3j (10.8\%), were identified encoded at Glu-B3 locus. There are many reports indicating different allelic frequencies representing the Glu$B 3$ locus in genotypes from different countries. Branlard et al. (2003) reported Glu-B3b in $10.0 \%$ of cultivars in France, $G l u-B 3 g$ in $49.0 \%$ and $G l u-B 3 d$ in $3.5 \%$. Other reports have also indicated the presence of $G l u-B 3 b$ and $G l u-B 3 g$ alleles in large numbers of cultivars (Jackson et al. 1996; Igrejas et al. 1999; Wang et al. 2009). Glu-B3b was present in higher percentage in $\mathrm{CZ}$ and $\mathrm{PZ}$ where warmer conditions prevail and $G l u-B 3 j(1 \mathrm{~B} / 1 \mathrm{R}$ translocation) in NHZ where comparatively cooler conditions prevail. Though SDSPAGE analyses showed three types of Glu-D3 alleles, the combination of both SDSPAGE and PCR based markers identified six alleles namely Glu-D3a (31.1\%), Glu-D3b (32.3\%), Glu-D3c (0.8\%), Glu-D3g (25.1\%), Glu-D3i (7.2\%), Glu-D3j (3.4\%) at Glu-D3 locus. In contrast, reports by Branlard et al. (2003), Igrejas et al. (1999) and Jackson et al. (1996) showed a higher percentage of the Glu-D3c allele and a lower percentage of the $G l u-D 3 b$ allele in European cultivars.

\section{Influence of Glu-1 and Glu-3 loci and their alleles on sedimentation volume and} mixograph parameters

SDS sedimentation volume and mixograph parameters reflect dough strength and mixing properties in bread wheats. High sedimentation volumes have been reported linked with stronger gluten and superior bread making quality. The effects of Glu-1 and Glu-3 loci on sedimentation volume and mixograph parameters are shown in Tables 3 and 4. Though, there was no significant difference among Glu-A1 allelic variants, Glu-Alb exhibited higher SDS-sedimentation volume in comparison to other alleles encoded by Glu-A1 locus. Reports by He et al. (2005), Liu et al. (2005), Tabiki et al. (2006) and Figueroa et al. (2009) indicated the stronger role of Glu-Al while Luo et al. (2001) and Ram et al. (2003) showed stronger role of $G l u-A 1 b$ in imparting gluten strength. There was significant effect of Glu-B1 $(p<0.01)$ and Glu-D1 $(p<0.001)$ loci on SDS-sedimentation volumes (Table 4). Among Glu-B1 alleles, Glu-B1i exhibited highly significant positive effect on SDS-sedimentation $(p<0.001)$. Similarly Glu-Dld showed significantly higher values of SDS-sedimentation $(p<0.001)$ as compared to Glu-Dla. There was no significant difference in sedimentation value between Glu-B1i and Glu-D1d allelic forms, however the alleles in combination exhibited highest sedimentation value $(p<0.0001)$ (Table 5) indicating their additive effect.

Glu-1 loci also influenced various mixograph parameters. The Glu-A1 exhibited significant positive effect on mixograph mixing peak time. Glu-Alb showed significant positive effect on mixograph peak time, peak slope and peak width. Glu-B1 locus showed significant effect on mixograph peak height and width at $8(p<0.05)$. Surprisingly, though Glu-B1i showed higher values of mixograph parameters, there was no statistically significant effect. Glu-D1 locus showed significant positive effect on mixograph width at $8(p<0.05)$. There was significant effect of Glu-D1 on mixing time as reported by He et al. (2005) and Hernández et al. (2012). 
Table 3. Effect of allelic variation of HMW-GS and LMW-GS subunits on sedimentation volume and mixograph parameters using Duncan multiple comparisons

\begin{tabular}{|c|c|c|c|c|c|c|c|c|c|}
\hline Locus & Allele & Frequency & Protein & Sed & MPT & Peak slope & $\begin{array}{l}\text { Peak } \\
\text { width }\end{array}$ & $\begin{array}{c}\text { Width at } \\
8.0\end{array}$ & Peak ht \\
\hline \multirow[t]{3}{*}{ Glu-Al } & $a$ & 53 & $11.3^{\mathrm{a}}$ & $9.5^{\mathrm{a}}$ & $2.6^{\mathrm{ab}}$ & $6.2^{\mathrm{a}}$ & $15.7^{\mathrm{ab}}$ & $4.3^{\mathrm{a}}$ & $56.9^{a}$ \\
\hline & $b$ & 148 & $11.2^{\mathrm{a}}$ & $9.3^{a}$ & $2.8^{\mathrm{a}}$ & $5.9^{\mathrm{ab}}$ & $16.1^{\mathrm{a}}$ & $4.7^{\mathrm{a}}$ & $57.0^{\mathrm{a}}$ \\
\hline & $c$ & 39 & $11.4^{\mathrm{a}}$ & $9.1^{\mathrm{a}}$ & $2.4^{\mathrm{b}}$ & $5.3^{\mathrm{b}}$ & $14.7^{b}$ & $4.5^{\mathrm{a}}$ & $55.3^{a}$ \\
\hline \multirow[t]{6}{*}{ Glu-B1 } & $a$ & 7 & $11.1^{\mathrm{a}}$ & $9.1^{\mathrm{b}}$ & $2.7^{\mathrm{a}}$ & $5.8^{\mathrm{a}}$ & $15.2^{\mathrm{a}}$ & $4.3^{\mathrm{a}}$ & $58.2^{\mathrm{a}}$ \\
\hline & $b$ & 68 & $11.1^{\mathrm{a}}$ & $9.1^{\mathrm{b}}$ & $2.8^{\mathrm{a}}$ & $5.8^{\mathrm{a}}$ & $15.6^{\mathrm{a}}$ & $4.7^{\mathrm{a}}$ & $54.3^{\mathrm{a}}$ \\
\hline & $c$ & 63 & $11.2^{\mathrm{a}}$ & $9.2^{\mathrm{b}}$ & $2.6^{\mathrm{a}}$ & $6.3^{\mathrm{a}}$ & $16.1^{\mathrm{a}}$ & $4.3^{\mathrm{a}}$ & $57.6^{\mathrm{a}}$ \\
\hline & $e$ & 9 & $11.6^{\mathrm{a}}$ & $8.9^{b}$ & $2.6^{\mathrm{a}}$ & $5.6^{\mathrm{a}}$ & $16.0^{\mathrm{a}}$ & $4.3^{a}$ & $57.2^{\mathrm{a}}$ \\
\hline & $i$ & 84 & $11.4^{\mathrm{a}}$ & $9.8^{\mathrm{a}}$ & $2.8^{\mathrm{a}}$ & $5.6^{\mathrm{a}}$ & $16.1^{\mathrm{a}}$ & $4.8^{\mathrm{a}}$ & $57.7^{\mathrm{a}}$ \\
\hline & others & 9 & - & - & - & - & - & - & - \\
\hline \multirow[t]{2}{*}{ Glu-D1 } & $a$ & 162 & $11.2^{\mathrm{a}}$ & $9.1^{\mathrm{b}}$ & $2.8^{\mathrm{a}}$ & $5.9^{\mathrm{a}}$ & $15.9^{\mathrm{a}}$ & $4.7^{\mathrm{a}}$ & $56.4^{\mathrm{a}}$ \\
\hline & $d$ & 78 & $11.4^{\mathrm{a}}$ & $9.8^{\mathrm{a}}$ & $2.7^{\mathrm{a}}$ & $5.7^{\mathrm{a}}$ & $15.6^{\mathrm{a}}$ & $4.4^{\mathrm{a}}$ & $57.4^{\mathrm{a}}$ \\
\hline \multirow[t]{4}{*}{ Glu-A3 } & $b$ & 44 & $11.2^{\mathrm{a}}$ & $9.7^{\mathrm{a}}$ & $2.9^{\mathrm{a}}$ & $6.1^{\mathrm{a}}$ & $16.2^{\mathrm{a}}$ & $4.7^{\mathrm{a}}$ & $56.8^{\mathrm{a}}$ \\
\hline & $c$ & 156 & $11.2^{\mathrm{a}}$ & $9.4^{\mathrm{a}}$ & $2.7^{\mathrm{a}}$ & $5.9^{\mathrm{a}}$ & $15.3^{\mathrm{a}}$ & $4.5^{\mathrm{a}}$ & $56.8^{\mathrm{a}}$ \\
\hline & $d$ & 25 & $11.5^{\mathrm{a}}$ & $9.3^{\mathrm{a}}$ & $2.6^{\mathrm{a}}$ & $5.8^{\mathrm{a}}$ & $15.4^{\mathrm{a}}$ & $4.7^{\mathrm{a}}$ & $56.9^{a}$ \\
\hline & $e / f$ & 135 & $11.2^{\mathrm{a}}$ & $9.1^{\mathrm{a}}$ & $2.6^{\mathrm{a}}$ & $5.5^{\mathrm{a}}$ & $15.1^{\mathrm{a}}$ & $4.8^{\mathrm{a}}$ & $54.9^{\mathrm{a}}$ \\
\hline \multirow[t]{6}{*}{ Glu-B3 } & $b$ & 70 & $11.3^{\mathrm{a}}$ & $9.3^{\mathrm{a}}$ & $2.7^{\mathrm{ab}}$ & $5.7^{\mathrm{bc}}$ & $15.8^{\mathrm{a}}$ & $4.5^{\mathrm{ab}}$ & $56.5^{\mathrm{a}}$ \\
\hline & $g$ & 60 & $11.1^{\mathrm{a}}$ & $9.5^{\mathrm{a}}$ & $2.9^{\mathrm{a}}$ & $5.9^{\mathrm{bc}}$ & $15.3^{\mathrm{a}}$ & $5.1^{\mathrm{a}}$ & $55.8^{\mathrm{a}}$ \\
\hline & $h$ & 39 & $11.1^{\mathrm{a}}$ & $9.5^{\mathrm{a}}$ & $2.7^{\mathrm{ab}}$ & $4.9^{\mathrm{c}}$ & $15.4^{\mathrm{a}}$ & $4.7^{\mathrm{ab}}$ & $56.2^{a}$ \\
\hline & $i$ & 35 & $11.4^{\mathrm{a}}$ & $8.9^{\mathrm{a}}$ & $2.4^{\mathrm{b}}$ & $6.5^{\mathrm{ab}}$ & $16.0^{\mathrm{a}}$ & $4.3^{b}$ & $56.9^{\mathrm{a}}$ \\
\hline & $j$ & 24 & $11.3^{\mathrm{a}}$ & $9.1^{\mathrm{a}}$ & $2.7^{\mathrm{ab}}$ & $7.3^{\mathrm{a}}$ & $16.4^{\mathrm{a}}$ & $4.1^{\mathrm{b}}$ & $58.9^{a}$ \\
\hline & others & 8 & - & - & - & - & - & - & - \\
\hline \multirow[t]{6}{*}{ Glu-D3 } & $a$ & 72 & $11.3^{\mathrm{a}}$ & $9.4^{\mathrm{a}}$ & $2.6^{\mathrm{ab}}$ & $5.8^{\mathrm{a}}$ & $15.9^{\mathrm{a}}$ & $4.4^{\mathrm{a}}$ & $56.2^{\mathrm{a}}$ \\
\hline & $b$ & 79 & $11.2^{\mathrm{a}}$ & $9.3^{\mathrm{a}}$ & $2.8^{\mathrm{a}}$ & $5.9^{\mathrm{a}}$ & $15.4^{\mathrm{a}}$ & $4.6^{\mathrm{a}}$ & $56.4^{\mathrm{a}}$ \\
\hline & $g$ & 57 & $11.0^{\mathrm{a}}$ & $9.0^{\mathrm{a}}$ & $2.8^{\mathrm{a}}$ & $5.8^{\mathrm{a}}$ & $16.2^{\mathrm{a}}$ & $4.8^{\mathrm{a}}$ & $56.8^{a}$ \\
\hline & $i$ & 16 & $11.4^{\mathrm{a}}$ & $9.2^{\mathrm{a}}$ & $2.7^{\mathrm{ab}}$ & $5.5^{\mathrm{a}}$ & $15.7^{\mathrm{a}}$ & $4.5^{\mathrm{a}}$ & $57.5^{\mathrm{a}}$ \\
\hline & $j$ & 8 & $11.3^{\mathrm{a}}$ & $9.3^{\mathrm{a}}$ & $2.3^{\mathrm{b}}$ & $6.7^{\mathrm{a}}$ & $16.1^{\mathrm{a}}$ & $4.3^{\mathrm{a}}$ & $57.9^{a}$ \\
\hline & others & 7 & - & - & - & - & - & - & - \\
\hline
\end{tabular}

Values followed by the similar superscript were in same group having non-significant statistical difference.

There was no significant difference on the effect of Glu-3 loci on sedimentation values. $G l u-A 3 c$ showed higher sedimentation value though not significant, as compared to Glu$A 3 b, d$ and null allele. The Glu-B3 allelic group $b, g$ and $h$ exhibited higher sedimentation value than allelic group $i$ and $j$ (Table 4). Glu-D3a and Glu-D3b allelic groups showed higher SDS-sedimentation as compared to Glu-D3 $g, i$ and $j$. Glu-A3 loci showed no significant effect on mixograph parameters. The variation at Glu-B3 loci significantly influenced the dough strength parameters like mixograph peak slope $(p<0.05)$ and width at 
Table 4. F-values as determined by ANOVA showing the effect of Glu-1 and Glu-3 loci on sedimentation volume and mixograph parameters

\begin{tabular}{|l|c|c|c|c|c|c|c|c|}
\hline \multicolumn{1}{|c|}{ Locus } & DF & $\begin{array}{c}\text { Protein } \\
(14 \%)\end{array}$ & $\begin{array}{c}\text { Sedimentation } \\
\text { value }\end{array}$ & $\begin{array}{c}\text { Mixing peak } \\
\text { time }\end{array}$ & Peak slope & $\begin{array}{c}\text { Peak } \\
\text { height }\end{array}$ & $\begin{array}{c}\text { Peak } \\
\text { width }\end{array}$ & $\begin{array}{c}\text { Width at } \\
8.0\end{array}$ \\
\hline$G l u-A 1$ & 2 & 1.4 & 1.4 & $5.7^{* *}$ & 2.0 & 0.7 & 2.5 & 2.0 \\
\hline$G l u-B 1$ & 4 & 1.8 & $3.3^{* *}$ & 1.7 & 1.1 & $3.3^{*}$ & 0.3 & $2.8^{*}$ \\
\hline$G l u-D 1$ & 1 & 2.3 & $17.5^{* * *}$ & 1.7 & 0.6 & 1.0 & 0.6 & $3.4^{*}$ \\
\hline$G l u-A 3$ & 3 & 0.8 & 0.9 & 2.0 & 0.5 & 0.3 & 0.6 & 0.7 \\
\hline$G l u-B 3$ & 4 & 1.1 & 1.1 & 2.1 & $5.5^{* *}$ & 0.9 & 0.5 & $3.4^{* *}$ \\
\hline$G l u-D 3$ & 4 & 0.3 & 0.8 & $2.6^{*}$ & 0.4 & 0.2 & 0.5 & 1.3 \\
\hline
\end{tabular}

DF: degree of freedom, *significant at $p<0.05, * *$ significant at $p<0.01, * * *$ significant at $p<0.001$.

Table 5. Effect of Glu-B1i and Glu-D1d alleles on sedimentation volume

\begin{tabular}{|c|c|c|c|c|c|c|c|c|}
\hline & \multicolumn{2}{|c|}{ Glu-Bli } & \multicolumn{2}{|c|}{ Non $G l u-B 1 i$} & \multirow{2}{*}{$\begin{array}{c}\text { Glu-Bli } \\
+ \\
\text { Glu-Dld }\end{array}$} & \multirow{2}{*}{$\begin{array}{c}\text { Non Glu-Bli } \\
+ \\
\text { Glu-Dla }\end{array}$} & \multirow{2}{*}{$\begin{array}{c}\text { Glu-Bli } \\
+ \\
\text { Glu-Dla }\end{array}$} & \multirow{2}{*}{$\begin{array}{c}\text { Non Glu-B1i } \\
+ \\
\text { Glu-Dld }\end{array}$} \\
\hline & Glu-Dld & Glu-Dla & Glu-Dld & Glu-Dla & & & & \\
\hline Mean & 10.5 & 9.4 & 9.5 & 8.8 & 10.5 & 8.8 & 9.4 & 9.6 \\
\hline Observation & 35 & 50 & 51 & 118 & 35 & 118 & 50 & 51 \\
\hline$t$-Test values & $3.66 * *$ & & $3.01 * *$ & & $6.84 * * *$ & & 0.7 & \\
\hline
\end{tabular}

There was highly significant effect of both the alleles on sedimentation volume and also exhibited strong additive effect. $* *, * * *$ indicate values that are significant at $p<0.001$ and $p<0.0001$ level of significance.

$8.0(p<0.01)$. Glu-B3g exhibited significantly higher mixograph peak time and width at 8 when compared to other Glu-B3 alleles. Glu-B3h exhibited higher dough stability by showing significantly lower mixograph peak slope as compared to other alleles. Glu-B3j $(1 \mathrm{~B} / 1 \mathrm{R}$ translocation) exhibited highest peak slope indicating the negative effect on dough strength. Glu-D3 locus showed significant effect on mixograph peak time $(p<0.05)$. Glu-D3b and Glu-D3g exhibited significantly higher mixograph peak time as compared to other alleles encoded at Glu-D3 loci.

\section{Discussion}

\section{Allelic diversity of HMW and LMW glutenins}

In the present investigation, allelic diversity of HMW and LMW glutenin subunits were studied in a set of 240 diverse Indian wheat cultivars representing different zones having varied climatic conditions. Though large numbers of studies have been conducted with regard to HMW glutenin composition and their effect on dough strength (Payne, 1987; Gupta and MacRitchie 1994), few reports are available on the combined effect of both HMW and LMW glutenins (Cornish et al. 2006). Therefore, both HMW glutenins and LMW glutenins were studied with respect to their allelic distribution and in relation to their effect on gluten strength as determined by sedimentation volume and mixograph 
parameters. There was reduction in the frequency of Glu-Alc during last 6 decades of wheat breeding in India while stronger Glu-A1 $a$ and $G l u-A 1 b$ alleles increased. However, concomitant with this, there was decrease in the frequency of strong allele (Glu-B1i) encoded at Glu-B1 locus. The strong allele Glu-D1d decreased between 1971 and 1990 and subsequently increased with the introduction of $1 \mathrm{~B} / 1 \mathrm{R}$ translocation. The data further demonstrated that the $75 \%$ of genotypes possessing Glu-Dla allele had Glu-B3g and $90 \%$ had $G l u-B 3 b$ allele. The occurrence of strong alleles such as Glu-B3g and Glu-B3b in $60 \%$ of the cultivars in India, in combination with a weak allele at the Glu-D1 locus, has indicated the technological value of these alleles. $15 \%$ of the total Indian cultivars carried $G l u-B 1 i$ in combination with Glu-D1d and $40 \%$ of these cultivars possessed Glu-B3b allele.

The data also indicated that the increased use of the $1 \mathrm{~B} / 1 \mathrm{R}$ translocation from the 1980 s onwards by wheat breeding programs in India resulted in the presence of the Glu$B 3 j$ allele in many of the cultivars released in recent years that led to reduction in gluten strength. Zone-wise analysis of the data indicated the prevalence of $1 \mathrm{~B} / 1 \mathrm{R}$ translocation in cultivars representing Northern Hills, North West and North East plains where cold conditions prevail during winter period as compared to $\mathrm{CZ}$ where warm and dry conditions exist. Earlier studies have also shown the presence of genes showing resistance to cold conditions in $1 \mathrm{~B} / 1 \mathrm{R}$ translocation lines. Although most of the $1 \mathrm{~B} / 1 \mathrm{R}$ translocation lines carried the Glu-D1b allele, $95 \%$ of them also carried either the Glu-B1a or the Glu$B 1 c$ alleles which are associated with weak gluten. Surprisingly not a single genotype with $1 \mathrm{~B} / 1 \mathrm{R}$ translocation had Glu-B1i allele. These data suggest that recently released varieties in India can be improved either by combining stronger alleles encoded by the $G l u$-B1 locus, such as Glu-B1i encoding HMW-GSs $17+18$, or by incorporating the Glu$B 3$ locus through recombinant breeding aimed at reducing the size of the translocated $1 \mathrm{~B} / 1 \mathrm{R}$ fragment. This is possible thanks to the availability of dense molecular maps and linked markers. Our unpublished results show that a combination of $2 *, 5+10$, and $17+18$ HMW-GSs can significantly enhance the gluten strength of $1 \mathrm{~B} / 1 \mathrm{R}$ translocation lines and, consequently, their bread making quality. There was significant increase in the gluten strength of backcross lines (BC3F5) developed using a marker for the Glu-B1i allele in a 1B/1R background.

\section{Effect of HMW and LMW glutenins on sedimentation volume and mixograph parameters}

There was significant effect of Glu-B1 and Glu-D1 loci on SDS-sedimentation volume as reported by several other workers (Payne 1987; He et al. 2005; Liu et al. 2005). However, Hernández et al. (2012) showed no significant effect of Glu-1 loci on SDS-sedimentation. Among Glu-B1 and Glu-D1 alleles, Glu-B1i and Glu-Dld showed strongest effects and negated the influence of alleles encoded at Glu-3 loci. Glu-A1b showed stronger effect on sedimentation volume and mixograph parameters as compared to Glu-Ala and $c$. Luo et al. (2001) also reported stronger relationship of Glu-A1b allele, however, He et al. (2005), Liu et al. (2005), Figueroa et al. (2009) and Tabiki et al. (2006) suggested the stronger 
role of Glu-Ala in quality parameters. Surprisingly, there was no significant effect of $G l u-B 1$ and $G l u-D 1$ loci on mixograph mixing time, but variation at Glu-A1 significantly influenced mixing time. He et al. (2005) showed strong influence of all the Glu-1 loci while Hernández et al. (2012) reported significant effect on mixograph peak time by only Glu-D1.

LMW-GS alleles like $G l u-A 3 c, G l u-B 3 b, G l u-B 3 g$ and $G l u-D 3 b$ were the predominant alleles present in Indian cultivars. Glu-A3b showed the stronger dough properties as reported earlier by Liang et al. (2010). However, He et al. (2005), Liu et al. (2005) and Maucher et al. (2009) reported stronger effect of $G l u-A 3 d$ on dough strength. There was no significant effect of any of the Glu-3 loci on SDS-sedimentation values. However, earlier reports of He et al. (2005) and Liu et al. (2005) indicated the significant effect of Glu-3 loci on SDS-sedimentation value. This may be due to absence of strong allele Glu$B 1 i$ and lesser frequency of Glu-D1d in Chinese wheat cultivars. Hernández et al. (2012) reported significant effect of only Glu-B3 loci on SDS-sedimentation values. These discrepancies may be due to the difference in the genetic background of the cultivars used. There are very few reports of the effect of Glu-D3 locus and its allelic variant on quality parameters (He et al. 2005; Tabiki et al. 2006; Maucher et al. 2009). In this study, we included the new Glu-D3 alleles identified through PCR based markers: Glu-D3 $g, i$ and $j$. $G l u-D 3 b$ and $G l u-D 3 g$ exhibited stronger mixograph characteristics.

Overall, there was similarity in the order of the effect of Glu-1 and Glu-3 alleles on dough strength as reported by Cornish et al. (2006) and thus have greater utility in wheat quality improvement programs. Since Glu-Bli and Glu-D1b had very strong positive effect on dough strength, the effect of Glu-3 loci was assessed under non-Glu-B1i and Glu$D 1 d$ backgrounds. At Glu-A3 loci, there was no significant difference among Glu-A3 alleles on SDS-sedimentation volume when present in combination in non-Glu-B1i and $G l u-D 1 a$ background, but greater mean sedimentation value was shown by Glu-A3b followed by Glu-A3c. Glu-B3h exhibited significant effect $(p<.05)$ on sedimentation values followed by Glu-B3g and Glu-B3b in the background of Glu-Dla and non-Glu-B1i allelic combinations. Glu-B3j showed lowest sedimentation values. Glu-D3a and Glu-D3b showed similar SDS-sedimentation value when present in combination with non-Glu-B1i and Glu-Dla alleles. Overall, Glu-A3b, Glu-B3h and Glu-D3b alleles encoded at Glu-3 loci showed stronger gluten characteristics.

The study demonstrated the prevalence of Glu-A1b, Glu-B1i, Glu-Dla, Glu-A3c, Glu$B 3 b, G l u-B 3 g$ and $G l u-D 3 b$ alleles in Indian wheat cultivars. Recently developed cultivars exhibited decline in frequency of strong alleles Glu-Bli and Glu-Dld. The allelic combination that exhibited highest dough strength as measured by SDS-sedimentation value and mixograph parameters was Glu-A1b, Glu-B1i, Glu-D1d, Glu-A3b, Glu-B3g/h and $G l u-D 3 b$. This information can be useful in designing breeding program for the improvement of Indian bread wheat quality. 


\section{Acknowledgements}

Authors thankfully acknowledge the contribution of Dr. Ajay Verma, Senior Scientist and Dr. R. Sendhil, Scientist, DWR, Karnal for statistical analysis of data.

\section{References}

Appelbee, M.J., Mekuria, G.T., Nagasandra, V., Bonneau, J.P., Eagles, H.A., Eastwood, R.F., Mather, D.E. 2009. Novel allelic variants encoded at the Glu-D3 locus in bread wheat. J. Cereal Sci. 49:254-261.

Benito, C., Figueiras, A.M., Zaragoza, C., Gallego, F.J., de la Pena, A. 1993. Rapid identification of Triticeae genotypes from single seeds using the polymerase chain reaction. Plant Mol. Biol. 21:181-183.

Branlard, G., Dardevet, M. 1985. Diversity of grain protein and bread wheat quality. II. Correlation between high molecular weight subunits of glutenin and flour quality characteristics. J. Cereal Sci. 3:345-354.

Branlard, G., Dardevet, M., Amiour, N., Igrejas, G. 2003. Allelic diversity of HMW and LMW glutenin subunits and omega gliadins in French bread wheat (Triticum aestivum L). Genet. Crop Evol. 50:669-679.

Carter, B.P., Morris, C.F., Anderson, J.A. 1999. Optimising the SDS sedimentation test for end use quality selection in a soft white and club wheat breeding program. Cereal Chem. 76:907-911.

Cornish, G.B., Békés, F., Eagles, H.A., Payne, P.I. 2006. Prediction of dough properties for bread wheats. In: Wrigley, C.W., Békés, F., Bushuk, W. (eds), Gliadin and Glutenin. The Unique Balance of Wheat Quality. AACCI Press. St Paul, Min., USA. pp. 243-280.

Figueroa, J.D.C., Maucher, T., Reule, W., Peña, R.J. 2009. Influence of high molecular weight glutenins on viscoelastic properties of intact wheat kernel and relation to functional properties of wheat dough. Cereal Chem. 86:139-144.

Gupta, R.B., Shepherd, K.W. 1990. Two-step one dimensional SDS-PAGE analysis of LMW subunits of glutenin. I. Variation and genetic control of the subunits in hexaploid wheats. Theor. Appl. Genet. 80:65-74.

Gupta, R.B., MacRitchie, F. 1994. Allelic variation at glutenin subunit and gliadin loci, Glu-1, Glu-3 and Gli-1 of common wheats. II. Biochemical basis of the allelic effects on dough properties. J. Cereal Sci. 19:19-29.

He, Z.H., Liu, L., Xia, X.C., Liu, J.J., Peña, R.J. 2005. Composition of HMW and LMW glutenin subunits and their effects on dough properties, pan bread, and noodle quality of Chinese bread wheats. Cereal Chem. 82:345-350.

Hernández, Z.J.E., Figueroa, J.D.C., Rayas-Duarte, P., Martínez-Flores, H.E., Arámbula, G.V., Luna, G.B., Peña, R.J. 2012. Influence of high and low molecular weight glutenins on stress relaxation of wheat kernels and the relation to sedimentation and rheological properties. J. Cereal Sci. 55:344-350.

Igrejas, G., Guedes-Pinto, H., Cardine, V., Branlard, G. 1999. The high and low molecular weight glutenin subunits and omega gliadin composition of bread and durum wheats commonly grown in Portugal. Plant Breed. 118:297-302.

Ikeda, T.M., Branlard, G., Peña, R.J., Takata, K., Liu, L., He, Z., Lerner, S.E., Kolman, M.A., Yoshida, H., Rogers, W.J. 2008. International collaboration for unifying Glu-3 nomenclature system in common wheats. In: International Wheat Genetics Symposium, Brisbane, Australia. http://ses.library.usyd.edu.au/bitstream/2123/3281/1/O42.pdf

Jackson, E.A., Morel, M.H., Sontag-Strohm, T., Branlard, G., Metakovsky, E.V., Redaelli, R. 1996. Proposal for combining the classification systems of alleles of Gli-1 and Glu-3 loci in bread wheat (Triticum aestivum L.). J. Genet. Breed. 50:321-336.

Liang, D., Tang, J., Peña, R.J., Singh, R., He, X., Shen, X., Yao, D., Xia, X., He, Z. 2010. Characterization of CIMMYT bread wheats for high and low-molecular weight glutenin subunits and other quality-related genes with SDS-PAGE, RP-HPLC and molecular markers. Euphytica 172:235-250.

Liu, L., He, Z.H., Yan, J., Zhang, Y., Xia, X., Peña, R.J. 2005. Allelic variation at the Glu-1 and Glu-3 loci, presence of the 1B.1R translocation, and their mixographic properties in Chinese bread wheats. Euphytica 142:197-204.

Liu, L., Ikeda, T.M., Branlard, G., Peña, R.J., Rogers, W.J., Lerner, S.E., Kolman, M.A., Xia, X., Wang, L., Ma, W., Appels, R., Yoshida, H., Wang, A., Yan, Y., He, Z. 2010. Comparison of low molecular weight glutenin 
subunits identified by SDS-PAGE, 2-DE, MALDI-TOF-MS and PCR in common wheat. BMC Plant Biology 10:124.

Luo, C., Griffin, W.B., Branlard, G., McNeil, D.L. 2001. Comparison of low and high molecular weight wheat glutenin allele effects on flour quality. Theor. Appl. Genet. 102:1088-1098.

Maucher, T., Figueroa, J.D.C., Reule, W., Peña, R.J. 2009. Influence of low molecular weight glutenins on viscoelastic properties of intact wheat kernels and their relation to functional properties of wheat dough. Cereal Chem. 86:372-375.

Payne, P.I., Lawrence, G.J. 1983. Catalogue of alleles for the complex gene loci, Glu-A1, Glu-B1, and Glu-D1 which code for the high-molecular-weight subunits of glutenin in hexaploid wheat. Cereal Res. Commun. 11:29-35.

Payne, P.I. 1987. Genetics of wheat storage protein and the effect of allelic variation on bread making quality. Ann. Rev. Plant Physiol. 38:141-153.

Ram, S. 2003. High molecular weight glutenin subunit composition of Indian wheats and their relationships with dough strength. J. Plant Biochem. Biotech. 12:151-155.

Ram, S., Sharma, S., Verma, A., Tyagi, B.S., Peña, R.J. 2011. Comparative analysis of LMW glutenin alleles in bread wheat using allele-specific PCR and SDS-PAGE. J. Cereal Sci. 54:488-493.

Shewry, P.R., Halford, N.G., Lafiandra, D. 2003. Genetics of wheat gluten proteins. Adv. Genet. 49:111-184.

Sharma, S., Ram, S., Gupta, R., Sharma, I. 2013. Development of functional marker for distinguishing Glu-B3b allele of LMW-GS found in Indian common wheat cultivars. J. Cereal Sci. 57:245-248.

Singh, N.K., Hephers, K.W., Cornish, G.B. 1991. A simplified SDS-PAGE procedure for separating LMW subunits of glutenin. J. Cereal Sci. 14:203-208.

Tabiki, T., Ikeguchi, I., Ikeda, M. 2006. Effects of high molecular weight and low molecular weight glutenin subunit alleles in common wheat flour quality. Breeding Sci. 56:131-136.

Wang, L., Li, G., Peña, R.J., Xia, X., He, Z. 2010. Development of STS markers and establishment of multiplex PCR for Glu-A3 alleles in common wheat (Triticum aestivum L.). J. Cereal Sci. 51:305-312.

Wang, L.H., Zhao, X.L., He, Z.H., Ma, W., Appels, R., Peña, R.J., Xia, X.C. 2009. Characterization of lowmolecular-weight glutenin subunit Glu-B3 genes and development of STS markers in common wheat (Triticum aestivum L.). Theor. Appl. Genet. 118:525-539.

Zhang, W., Gianibelli, M.C., Rampling, L., Gale, K.R. 2004. Characterization and marker development for low molecular weight glutenin genes from Glu-A3 alleles of bread wheat (Triticum aestivum L.). Theor. Appl. Genet. 108:1409-1419.

Zhao, X.L., Ma, W., Gale, K.R., Lei, Z.S., He, Z.H., Sun, Q.X., Xia, X.C. 2007a. Identification of SNPs and development of functional markers for LMW-GS genes at Glu-D3 and Glu-B3 loci in bread wheat (Triticum aestivum). Mol. Breed. 20:223-231.

Zhao, X.L., Xia, X.C., He, Z.H., Lei, Z.S., Appels, R., Yang, Y., Sun, Q.X., Ma, W. 2007b. Novel DNA variations to characterize low molecular weight glutenin Glu-D3 genes and develop STS markers in common wheat. Theor. Appl. Genet. 114:451-460.

\section{Electronic Supplementary Material (ESM)}

Electronic Supplementary Material (ESM) associated with this article can be found at the website of CRC at http://www.akademiai.com/content/120427/

Electronic Supplementary Table S1. Allelic composition of both HMW and LMW glutenin subunits from 240 Indian wheat cultivars 